\title{
CORRESPONDENCE
}

\section{Role of induced sputum in interstitial lung disease}

\author{
To the Editor:
}

We appreciated the article by Fireman and LeRman [1] recently published in the European Respiratory Journal, about the possible role of induced sputum to assess and diagnose interstitial lung disease (ILD). We also reported that induced-sputum samples from patients with newly diagnosed and untreated pulmonary sarcoidosis contained significantly more total cells, lymphocytes, and epithelial cells when compared to that recovered from healthy volunteers. Moreover, lymphocyte counts in induced sputum were comparable to those from bronchial wash and bronchoalveolar lavage (BAL), although there was no correlation among lymphocyte counts in samples recovered with the three different techniques [2].

We have recently extended our knowledge on induced sputum in ILD, particularly in hypersensitivity pneumonitis (HP) and in idiopathic pulmonary fibrosis (IPF). When compared to 10 healthy subjects (three male, mean age $31 \pm 7 \mathrm{yrs}$ ), eight HP patients (six male, mean age $54 \pm 10$ yrs) had higher (mean \pm SD) total cell, lymphocyte and eosinophil counts in induced sputum $\left(7.7 \pm 5.1 \times 10^{5}\right.$ cells $\cdot \mathrm{mL}^{-1}$ versus $3.6 \pm 2 \times 10^{5}$ cells $\cdot \mathrm{mL}^{-1}$, $\mathrm{p}<0.02 ; 4.3 \pm 3.4 \%$ versus $1.2 \pm 2 \%, \mathrm{p}<0.02 ; 4.3 \pm 8.2 \%$ versus $0 \%, \mathrm{p}<0.02)$. Moreover, in induced sputum from seven IPF patients (six male, mean age $54.3 \pm 10.6 \mathrm{yrs}$ ), the percentage of lymphocytes was higher than that of healthy subjects (7.7 \pm $7.7 \%$ versus $1.2 \pm 2 \%, \mathrm{p}<0.02$ ). These results further confirm that induced sputum is a promising technique in assessing ILD.

However, although it has been demonstrated that cellular profiles from induced sputum correspond to those from BAL in sarcoidosis [2, 3] and in nongranulomatous ILD [3], induced sputum cannot entirely replace BAL in assessing ILD. Unlike BAL, induced sputum primarily samples the more proximal airways, with neutrophil-rich secretion. Consequently, the percentage of neutrophils in induced sputum samples was several times higher than in bronchial wash and in BAL samples both in sarcoidosis patients and healthy subjects [2]. This finding was confirmed by other authors by comparing the percentage of neutrophils from induced sputum to that from BAL, both in patients with nongranulomatous ILD [3] and with pneumoconiosis [4]. Additionally, BAL is an invasive but safe investigative tool in ILD, though, to date, no specific studies have been undertaken to evaluate the safety and functional effects of sputum induction on patients with ILD. Additionally, induced sputum can cause bronchoconstriction and sometimes a fall in arterial oxygen saturation in asthmatics and smokers [5], so airway function is closely monitored throughout the procedure, and patients at risk are pretreated with bronchodilators [6].

In conclusion, we believe that although induced sputum has already provided some promising results in assessing interstitial lung disease, its diagnostic role has not yet been well defined. Thus, induced sputum should only be used with caution, as a complementary tool to bronchoalveolar lavage, both in research and in the clinical monitoring of patients with interstitial lung disease.

R. D'Ippolito, A. Chetta, D. Olivieri

Istituto di Malattie Respiratorie, Universitá di Parma, Viale G. Rasori, 10-43100 Parma, Italy. Fax: 390521292615.

\section{References}

1. Fireman E, Lerman Y. Possible future of induced sputum in interstitial lung disease. Eur Respir J 2000; 15: 240-242.

2. D'Ippolito R, Foresi A, Chetta A, et al. Induced sputum in patients with newly diagnosed sarcoidosis. Comparison with bronchial wash and BAL. Chest 1999; 115: 1611-1615.

3. Fireman E, Topilsky I, Greif J, et al. Induced sputum compared to bronchoalveolar lavage for evaluating patients with sarcoidosis and nongranulomatous interstitial lung disease. Respiratory Medicine 1999; 93: 827-834.

4. Fireman E, Greif J, Schwarz Y, et al. Assessment of hazardous dust exposure by BAL and induced sputum. Chest 1999; 115: 1720-1728.

5. Castagnaro A, Chetta A, Foresi A, D'Ippolito R, Malorgio R, Olivieri D. Effect of sputum induction on spirometric measurements and arterial oxygen saturation in asthmatic patients, smokers, and healthy subjects. Chest 1999; 116: 941-945.

6. Wong HH, Fahy JV. Safety of one method of sputum induction in asthmatic subjects. Am J Respir Crit Care Med 1997; 156: $299-233$.

\section{From the authors:}

We are very pleased by the interest shown in our paper "Possible future of induced sputum in interstitial lung diseases" [1] by this distinguished group of investigators. They wrote a fine paper in which they presented data very similar to ours in terms of the high levels of lymphocytes that can be recovered in sputum of patients with sarcoidosis compared to healthy controls [3]. This finding reflects the main difference between the differential profile of cells recovered from sputum in this group of diseases (i.e. high percentage of lymphocytes) and the differential counts in samples of asthmatics patients (i.e. high percentage of eosinophils).

The main difference between our data and those of D'IPPOLITo et al. [3] is that we performed one step further in search of a more specific diagnostic value to be derived from the results of the sputum cells analysis in interstitial lung disease (ILD). We also looked at the CD4/CD8 ratio. It is known that the presence of lymphocytosis alone in bronchoalveolar lavage (BAL) is not discriminative for sarcoidosis insofar as there are numerous other diseases (e.g. nonsarcoid ILD, multiple pulmonary infections, noninfectious identified pulmonary inflammation, and a variety of neoplasms involving the lung and bronchial hyperactivity) that also show increased lymphocytes in BAL fluid specimens [4]. The CD4/CD8 ratio, however, was found to be helpful for distinguishing sarcoidosis from other diseases [5]. Indeed, CD4/CD8 also has prognostic value in the estimation of favourable response to steroids for other nongranulomatous lung diseases (i.e. idiopathic pulmonary fibrosis, hypersensitivity pneumonitis), and 
this capability bestows even further value to induced sputum testing [6].

As to the safety of sputum induction, this technique was found to be free of risk in patients with asthma of varying severity $[7,8]$ and in patients with chronic obstructive pulmonary disease (COPD) [9]. The sputum induction procedure produces a minimal fall in forced expiratory volume in one second (FEV1) which can be inhibited by pretreatment with salbutamol [10].

With regard to the decrease of arterial oxygen saturation $\left(\mathrm{S}_{\mathrm{a}}, \mathrm{O}_{2}\right)$ during the induction of sputum, the results are still controversial: some reports show a slight fall in $\mathrm{Sa}_{\mathrm{a}} \mathrm{O}_{2}$ which was not clinically significant [9], while others show more significant effects [10]. In light of these inconsistencies, we suggest that the effect of induced sputum on the arterial oxygen saturation in patients with ILD must be monitored during sputum induction. This does not distract from the fact that induced sputum continues to be a much less invasive technique when compared with bronchoalveolar lavage.

In conclusion, we do not propose that induced sputum should replace bronchoalveolar lavage, transbronchial biopsy or other similar techniques but that it serve as another complementary or supplementary test that can be added to those recommended by the American Thoracic Society and European Respiratory Society executive committee for the first evaluation of patients with sarcoidosis, that it serve as another marker of activity to those already proposed as being potential diagnostic aids or indices of activation [11]. Our data show that analysis of CD4/CD8 cell subsets by induced sputum can be as helpful as BAL analysis in diagnosing sarcoidosis, and that it has prognostic value in patients with idiopathic pulmonary fibrosis, for whom there are clinical contraindications for undergoing bronchoscopy or when, for any other reasons, tissue samples are not available.

E Fireman*, Y. Lerman ${ }^{+}$,

*Institute of Pulmonary and Allergic Diseases, Tel Aviv Sourasky Medical Center, ${ }^{+}$The Occupational Health and Rehabilitation Institute, Ra'anana, The Sackler Faculty of Medicine, Tel-Aviv University, Tel-Aviv, Israel. Fax: 97236974601.

\section{References}

1. Fireman E, Lerman Y. Possible future of induced sputum in interstitial lung disease. Eur Respir J 2000; 15: 240-242.

2. Fireman E, Topilsky I, Greif J, et al. Evaluation of interstitial lung by induced sputum compared to bronchoalveolar lavage. Respir Med 1999; 33: 827-834.

3. D'Ippolito R, Foresi A, Chetta A, et al. Induced sputum in patients with newly diagnosed sarcoidosis. Chest 1999; 115: $1611-1615$

4. Rosen Y, Vulentin JC, Perschuck LP, Silverstein E. Sarcoidosis: from the pathologist's vantage point. Pathol Annu 1979; 14: 405-439.

5. Winterbauer RH, Lammert J, Selland M, et al. Bronchoalveolar lavage cell population in the diagnosis of sarcoidosis. Chest 1993; 104: 352-361.

6. Fireman E, Vardinon N, Burke M, et al. The prognostic and diagnostic value of T-lymphocytes subtypes analysis in idiopathic pulmonary fibrosis. Eur Respir $J$ 1998; 11: 706-711.

7. Wong HH, Fahy JV. Safety of one method of sputum induction in asthmatic subjects. Am J Respir Crit Care Med 1997; 156: 299-303.

8. Tarodo de la Fuente P, Romagnoli M, Godard P, Bousquet J, Chanez P. Safety of inducing sputum in patients with asthma of varying severity. Am J Respir Crit Care Med 1998; 157: $1127-1130$.
9. Bhowmik A, Seemungal T, Sapsford RJ, Devalia JL, Wedzica JA. Comparison of spontaneous and induced sputum for the investigation of airway inflammation in chronic obstructive pulmonary disease. Thorax 1998; 53: 953-956.

10. Castagno A, Chetta A, Foresi A, D'Ippolito R, Malorgio R, Olivieri D. Effect of sputum induction on spirometric measurements and arterial oxygen saturation in asthmatic patients, smokers, and healthy subjects. Chest 1999; 116: 941-945.

11. Statement on Sarcoidosis - The Joint Statement of the ATS ERS and VASOG adopted by the ATS and ERS executive committee, February 1999. Am J Respir Crit Care Med 1999; 160: 736-755.

\section{Smoking and asthma}

\section{To the Editor:}

We read with interest the paper of SIROUX et al. [1] who analysed the relationship between smoking and asthma severity amongst 347 asthma patients in the Epidemiological study on the Genetics and Environment of Asthma, bronchial hyperresponsiveness and atopy (EGEA) study. They found that smoking increases asthma severity and asthma patients were twice as likely to quit smoking as controls.

We have comparable data on smoking habits and asthma severity for a group of 1,570 asthma patients in Salford, North West England [2]. Details of patients seen by General Practitioners $(n=653)$ for their asthma were obtained from the Salford Asthma Register [3]. Details of patients attending the hospital chest clinic for their asthma $(n=700)$ and those who were admitted to the hospital as an emergency $(n=217)$ were obtained from the Hope Hospital Chest Clinic database. We also have data on the smoking habits of a control group based on a postal survey of local residents. We received 1,102 replies (out of 2,000 questionnaires sent). We found the prevalence of current smoking amongst the groups to be as follows: General population 27.5\%; "Mild Asthma" (General Practice Clinic) 19.6\%; "Moderate Asthma" (Hospital Clinic) 23\%; "Severe Asthma" (Hospital Admission) 32\%. Our data is therefore in strong agreement with the data of SIROUX et al. [1], asthmatic patients in Salford who smoke tend to have more severe disease and thus are more likely to be seen in clinic or be admitted for their asthma.

In the EGEA study, patients with asthma were twice as likely as controls to describe themselves as exsmokers. This relationship was very different in Salford where asthma patients were less likely to have ever smoked than controls but we found only a weak tendency for asthma patients to quit smoking: Controls 25\% exsmokers, "Mild asthma" 26.5\%, "Moderate Asthma" 30\%, "Severe asthma" 24\%. Salford patients with severe asthma were least successful at quitting the habit. We submit that despite their illness, patients with asthma find it difficult to stop smoking and hence more education and awareness is needed to prevent young people from taking up this dangerous habit.

\section{A. Raghuram, B.R. O'Driscoll}

Dept of Respiratory Medicine, Hope Hospital, Salford, M6 8HD, UK. Fax: 441617874328.

\section{References}

1. Siroux V, Pin I, Oryszczyn MP, Le Moual N, Kauffmann F. Relationship of active smoking to asthma and asthma severity in the EGEA study. Eur Respir J 2000; 15: 470-477. 
2. Raghuram A, Houghton CM, Ansted SJ, O'Driscoll BR. Smoking habits of asthma patients in Salford (Northwest England). Eur Respir J 1999; 14: Suppl. 30, 139s.

3. Ansted SJ, McDowall D, O'Driscoll BR. The Salford Asthma Register: a mechanism for auditing a district asthma population and supporting GP asthma care. Thorax 1998; 53: Suppl. 4, A75.

\section{From the author:}

Despite a different way of assessing asthma severity, RAGHURAM et al. [1] confirm our results [2] that active smoking relates to asthma severity. They concluded from their study conducted in Salford that asthma patients were less likely than controls to have ever smoked, but according to available data the prevalence of ever-smokers was not statistically different between asthmatics and controls (50 versus $53 \%$ respectively, $\mathrm{p}=0.23$ ).

Although the relationship of asthma to exsmoking was weaker, asthmatic smokers in Salford, as in the Epidemiological Study on the Genetics and Environment of Asthma, bronchial hyperresponsiveness and atopy (EGEA) study, quitted smoking significantly more often than controls (OR $(95 \% \mathrm{CI})=1.3(1.1-1.7), \mathrm{p}=0.008)$. The recruitment of asthmatics was probably based on a more restrictive definition of asthma in the EGEA study, which could explain the difference in OR between studies.

The conclusion that patients with severe asthma were least successful at quitting smoking is in accordance with the EGEA data in which we showed that the severity score was higher in current-smokers. These data and others strengthen the needs of more awareness and advice to prevent asthmatics from taking up smoking.

V. Siroux*, I. Pin ${ }^{\#}$, M.P. Oryszczyn*, N. Le Moual*, F. Kauffmann*

*Institut National de la Santé et de la Recherche Médicale U472, Villejuif, France. "Hôpital Albert Michalon, Grenoble, France.

\section{References}

1. Raghuram A, O'Driscoll BR. Smoking and asthma. Eur Respir $J$ (to be completed).

2. Siroux V, Pin I, Oryszczyn MP, Le Moual N, Kauffmann F. Relationships of active smoking to asthma and asthma severity in the EGEA study. Eur Respir J 2000; 15: 470-477.

\section{Nocturnal ventilation in neuromuscular diseases}

\section{To the Editor:}

The paper "Mechanisms underlying effects of nocturnal ventilation on daytime blood gases in neuromuscular diseases", by ANNANE et al. [1], published in the European Respiratory Journal, attempts to explain the still unclear mechanism whereby noninvasive nocturnal mechanical ventilation (NNMV) improves diurnal hypercapnia in neuromuscular patients with chronic respiratory failure.
They documented for the first time an increase in ventilatory $\mathrm{CO}_{2}$ response after prolonged NNMV induced normocapnia. The authors conclude that the improvement of daytime hypoventilation with NNMV, may represent an adaptation of the central chemoreceptors to the reduction of profound hypercapnia during sleep or reflect changes in the quality of sleep.

The first mechanism, however, cannot explain $\mathrm{CO}_{2}$ normalization after NNMV in central alveolar hypoventilation where respiratory drive may not be restored [2]. On the other side a normal mean $\mathrm{CO}_{2}$ tension in arterial blood $\left(\mathrm{Pa}_{\mathrm{a}} \mathrm{CO}_{2}\right)$ was obtained at the first year when the mean $\mathrm{CO}_{2}$ ventilatory response had increased $84 \%$ but only from $1.33-2.45 \mathrm{~L} \cdot \mathrm{min}^{-1} \cdot \mathrm{kPa}^{-1}$, a range which may be observed in many hypercapnic patients. However, considering individual data shown (fig. 1 of the original article) at $1 \mathrm{yr}$, though $\mathrm{Pa}, \mathrm{CO}_{2}$ was decreased in every patient [1], ventilatory drive was virtually unchanged in several for whom another explanation must be sought. At any rate, it may be difficult to decide if an increased drive is the cause or the result of NNMV induced normocapnia, since concomitant $\mathrm{HCO}_{3}$ decrease enhances central drive [3].

Accepting that normal minute ventilation $(V \mathrm{E}) / P \mathrm{a}, \mathrm{CO}_{2}$ is not $<6 \mathrm{~L} \cdot \mathrm{min}^{-1} \cdot \mathrm{kPa}^{-1}$ only three patients fell into that category, that is a substantial number of patients who normalized their $P \mathrm{a}, \mathrm{CO}_{2}$ remained however with depressed $V \mathrm{E} / P \mathrm{a}, \mathrm{CO}_{2}$ response. In two patients [1], $\mathrm{Pa}, \mathrm{CO}_{2}$ increased at the third year $\left(P \mathrm{a}, \mathrm{CO}_{2}>6.6 \mathrm{kPa}\right.$, fig. $1 \mathrm{~b}$ of the original article). It would be interesting to know their $V \mathrm{E} / P \mathrm{a}, \mathrm{CO}_{2}$ slope evolution. Also at least two patients increased their $V^{2} \mathrm{E}$ slope $>1 \mathrm{yr}$ after beginning NNMV, it seems difficult to believe that resetting may take so long. In our experience, in patients without airway obstruction when nocturnal ventilation is adequate $P \mathrm{a}, \mathrm{CO}_{2}$ is normalized in a few days despite the fact that $P \mathrm{a}_{1} \mathrm{CO}_{2} /$ mouth occlusion pressure $(P 0.1)$ may remain indefinitely abnormal.

Figure 2 in the paper by ANNANE et al. [1] is difficult to understand. Considering the data shown the authors conclude that the reduction of diurnal $P \mathrm{a}, \mathrm{CO}_{2}$ correlated with the increase of slope. Is each point in this figure representative of the best result during the study irrespective of time? Were the maximum values in the $\mathrm{x}$ and $\mathrm{y}$ axis, time related? So if $9 / 14$ patients had a reduction in $P \mathrm{a}, \mathrm{CO}_{2}<1 \mathrm{kPa}$ and $7 / 14$ patients had a maximal reduction in the slope $<1 \mathrm{~L} \cdot \mathrm{min}^{-1} \cdot \mathrm{kPa}^{-1}$. If all patients had responded, no correlation could be found. Data correlation on the other side, does not necessarily imply causeeffect relationship.

In accordance with these considerations, the relationship between the ventilatory response to carbon dioxide and development of chronic hypercapnia remains unclear to us. We believe that the washout of the carbon dioxide stores [4] during nocturnal ventilation could explain the normalization of diurnal hypercapnia $[5,6]$.

\section{E.L. De Vito, A.J. Roncoroni}

Laboratorio Pulmonar, Instituto de Investigaciones Medicas "Alfredo Lanari" Universidada de Buenos Aires, Buenos Aires, Argentina. Address: Combatientes de Malvinas 3150, PC1427, Buenos Aires, Argentina. Fax: 54145148708.

\section{References}

1. Annane D, Quera-Salva MA, Lofaso F, et al. Mechanisms underlying effects of nocturnal ventilation on daytime blood gases in neuromuscular diseases. Eur Respir J 1999; 13: $157-162$.

2. Roncoroni AJ, Montiel G, Semeniuk G. Bilateral carotid body paraganglioma and central alveolar hypoventilation. Respiration 1993; 60: 243-246. 
3. Heinemann HO, Goldrin RM. Bicarbonate and the regulation of ventilation. Am J Med 1974; 57: 361-370.

4. Farhi LE, Rahn H. Dynamics of changes in carbon dioxide stores. Anesthesiology 1960; 21: 604-614.

5. De Vito EL, Montiel G, Berizzo EEA, Quadrelli SA, Roncoroni AJ. Is the washout of the $\mathrm{CO}_{2}$ stores the cause of improvement of the hypercapnia in patients with noninvasive mechanical ventilation? Am J Respir Crit Care Med 1996; 153: $605 \mathrm{~S}$.

6. De Vito EL, Raggio I, Roncoroni AJ. Study of $\mathrm{CO}_{2}$ stores during passive hyperventilation in dogs. Am J Respir Crit Care Med 1996; 153: 606S.

\section{From the authors:}

We think that the readers of the European Respiratory Journal should remember the following information from our paper [1]. Firstly, nocturnal intermittent positive pressure ventilation (NIPPV) improves chronic hypoventilation in neuromuscular disorders. This improvement continues in the long term. Secondly, the mechanisms on which the relief of chronic hypoventilation rely are complex. However, our data demonstrated that these mechanisms do not include change in muscle fatigue or lung mechanics. Thirdly, NIPPV reversed sleep disruption and increased respiratory drive. These changes closely paralleled the decrease in day-time arterial $\mathrm{CO}_{2}$ tension. As shown in fig. 2 in our original paper [1], there was a good relationship between the decrease in arterial $\mathrm{CO}_{2}$ tension and the increase in the slope of the rebreathing test. Moreover, as soon as 6 months after implementation of NIPPV, both arterial $\mathrm{CO}_{2}$ tension and respiratory drive were improved in almost all patients. At $1 \mathrm{yr}$, in two patients (i.e. patients 4 and 14) the slope of the $\mathrm{CO}_{2}$ rebreathing test remained unchanged. Patient 4 remained hypercapnic overtime (i.e. arterial $\mathrm{CO}_{2}$ tension above $6 \mathrm{kPa}$ ). In patient 14 central respiratory drive improved after $1 \mathrm{yr}$ (from 0.91 to $6.95 \mathrm{~L} \cdot \mathrm{min}^{-1} \cdot \mathrm{kPa}^{-1}$ ) and arterial $\mathrm{CO}_{2}$ tension was normalized (from 6.57 to $5.9 \mathrm{kPa}$ ). The decrease in arterial $\mathrm{CO}_{2}$ tension was associated with a decrease in $\mathrm{HCO}_{3}$. Given that the cellular mechanisms that allow respiratory responses to $\mathrm{CO}_{2}$ are still unclear [2], it is difficult to draw conclusions on which of the changes in central drive, arterial $\mathrm{CO}_{2}$ tension or $\mathrm{HCO}_{3}$ precede the others. The increased ventilation produced by inhaled $\mathrm{CO}_{2}$ varies considerably in conscious humans [2], and in our laboratory, the lower normal value is $3.75 \mathrm{~L} \cdot \mathrm{min}^{-1} \cdot \mathrm{kPa}^{-1}$. Then, almost all patients reached this cut-off value by the third year after NIPPV initiation.

In conclusion, in neuromuscular and chest wall disorders like those evaluated in this study, nocturnal intermittent positive pressure ventilation related relief of chronic hypoventilation does not rely on change in muscle strength or lung mechanics, and is likely to be associated with changes in control of breathing. The mechanisms of improved central respiratory drive need further investigation.

\section{Annane*, P. Gajdos*, J.C. Raphael*, F. Lofaso ${ }^{\#}$}

*Service do Réanimation médicale, and ${ }^{~}$ Service d'explorations fonctionelles respiratoires, Hôpital Raymond Poincaré, 104 boulevard Raymond Poincaré, 92380 Garches, France. Fax: 33147107783.

\section{References}

1. Annane D, Quera-Salva MA, Lofaso F, et al. Mechanisms underlying effects of nocturnal ventilation on daytime blood gases in neuromuscular diseases. Eur Respir J 1999; 13: $157-162$.
2. Cherniak NS, Altose M. Control of ventilation: Central chemoreceptors. In: Crystal RG, West JB, Weibel ER, Barnes PJ, eds. The lung: Scientific Foundation. Philadelphia, PA, USA, Lippincott Raven, 1997; pp. 1767-1776.

\section{Low asthma prevalence in Turkish chil- dren}

To the Editor:

We read the article "Lower prevalence of asthma and atopy in Turkish children living in Germany" by KABESCH et al. [1] with great interest. Asthma prevalence appears to be affected by genetic background as well as atopy, and enviromental factors. The recently published International Study of Asthma and Allergies in Childhood (ISAAC) report documents lower prevalences in Eastern Europe, Greece and Russia $(<5 \%)$ than in western countries, and Turkey is also among these low prevalence countries regarding figures reported in epidemiological studies. A nationwide epidemiological study including an ISAAC-based questionnaire was conducted among 46,812 children aged $0-17$ yrs residing in 27 provinces in Turkey in 1996, and the lifetime and current (within last 12 months) prevalences of asthma were 14.7 and $2.8 \%$ respectively [3]. Personal and familial atopy were the most prominent risk factors for occurrence of asthma in children. The current prevalences of asthma and wheezing were higher among children residing in coastal areas than in those living inland. The prevalences among adult Turkish immigrants reported from Sweden and Belgium are similar to the mean figures for Europe [4, 5].

Germany simultaneously received workers not only from Turkey but also from many eastern countries during the 1960s. The workers were only accepted after a detailed medical examination (chest radiography, total blood count, urine analysis, physical examination, etc.) and were mostly from a low socioeconomic class. However, this selection of healthy workers was later de facto omitted, and Germany received many political refugees after 1980. At present, the Turkish minority makes up $2 \%$ of the population of Germany. Although some of the Turks living in this country have German citizenship, most of them continue to have an active relationship with their relatives in Turkey and frequently visit their homeland. They have usually preserved their living and dietary habits despite this long residency period abroad. The breastfeeding rates are close to $90 \%$. The children spend most of their first years at home with their parents, and those born in Turkey receive bacille Calmette-Guérin vaccination routinely. Although the number of people within the same house is declining, it is higher than the European average. There is no detailed documentation regarding the ventilation and heating characteristics of their houses. The rate of having pets at home is presumably rising, but is lower than the figure for Europe [6].

Recent epidemiological studies have revealed significant differences in dietary habits between children in the preschool and school age groups. The consumption of poultry, fish, fresh fruit and vegetables increases with age. There are also differences in dietary intake between people residing in different regions of Turkey. Fresh fruit and vegetables, fish and vegetable oil are less frequently consumed in Eastern Turkey, and fish is consumed most commonly in Northern Turkey [7]. Although there is no detailed information about the dietary intake of Turkish immigrants in Germany, changes in dietary intake have been reported among Turkish immigrants in Sweden [8]. 
Epidemiological studies in groups with different prevalences within the same population are valuable in revealing the associated risk factors. We believe that studies to be carried out in co-ordination with foreign institutions among Germans, Turkish immigrants and citizens in Turkey will provide valuable information, especially for the prevention of asthma.

\section{A.F. Kalyoncu, Z.T. Toros Selçuk}

Hacettepe University, School of Medicine, Dept of Chest Diseases, Sihhiye, Ankara 06100, Turkey. Fax: 903123100809.

\section{References}

1. Kabesch M, Schaal W, Nicolai T, von Mutius E. Lower prevalence of asthma and atopy in Turkish children living in Germany. Eur Respir J 1999; 13: 577-582.

2. The International Study of Asthma and Allergies in Childhood (ISAAC) Committee. Worldwide variation in prevalence of symptoms of asthma, allergic rhinoconjunctivitis, and atopic eczema: ISAAC. Lancet 1998; 351: 1225-1232.

3. Türktas I, Selçuk ZT, Kalyoncu AF. Prevalence of asthma and wheezing in Turkish children. Eur Respir J 1998; 12: 52s (abstract).

4. Kalyoncu AF, Stålenheim G. Survey on the allergic status in a Turkish population in Sweden. Allergol Immunopathol 1993; 21: 11-14

5. Vermeire $\mathrm{P}$, van Hoof K, Willemen M, Weyler J, Nelen V, Standaert B. Duration since immigration and reporting of asthma symptoms among young adults of Turkish nationality in Antwerp. Eur Respir J 1994; 7: Suppl. 18, 377s (abstract).

6. Zentrum für Turkeistudien. Das Bild der Auslander in der Öffentlichkeit. Opladen, Leske + Budrich, 1995.

7. Pekcan G, Karaagaoglu N. State of nutrition in Turkey Workshop on promoting food-based dietary guidelines and nutrition education in the Near-East region. Amman, 16-19. November 1998

8. Hjern A, Koçtürk-Runefors T, Jeppson O. Food habits and infant feeding in newly resettled refugee families from Chile and the Middle East. Scand J Prim Health Care 1990; 8: $145-150$.

\section{From the authors:}

We are grateful for the comments contributed by A.F Kalyoncu and Z.T. Selçuk regarding our article "Lower prevalence of asthma in Turkish children living in Germany" [1]. This letter adds further insight into the most recent epidemiological data available on childhood asthma in Turkey. We agree that a wide array of living conditions and changes in allergen exposure as well as dietary habits might influence the prevalence of asthma and atopy in children of different ethnic origins. It can also be speculated that risk factors such as breastfeeding, vaccination status, crowding and housing may contribute to the differences observed in comparisons of asthma prevalence between different countries.

We found a lower prevalence of asthma as well as atopy and bronchial hyperresponsiveness in Turkish children living in Germany compared to their German peers. A similar study, evaluating allergic sensitization, wheezing and eczema in Turkish children living in Berlin, Germany also reported lower levels of allergic diseases in these children [2]. Analysing small subgroup samples of these children, the study found an association between the degree of assimilation into a German lifestyle and the increase in atopic diseases. However, this does not sufficiently explain the low prevalence of asthma and atopy observed in Turkish children living in Germany compared to Turkish children living in Turkey. SeLçuk and coworkers [3] report a lifetime asthma prevalence of $14.7 \%$ in a nationwide Turkish survey of 46,813 children between 0 and $17 \mathrm{yrs}$ of age using an ISAAC-based questionnaire. This data is comparable to the range of asthma prevalence $(9.8-17.4 \%)$ reported previously in studies from Turkey [4-7]. Therefore, it further supports our finding that the lifetime prevalence of asthma is significantly lower in Turkish children living in Germany $(5.3 \%)$ compared to those living in Turkey [1]. Recent reports from Turkey indicate that the asthma prevalence is higher in coastal and metropolitan areas than in rural and inland regions [3]. As no information is available to us regarding the origin of Turkish immigrants to Germany, we cannot rule out the possibility that these immigrants were drawn mainly from rural and inland areas of Turkey. However, the children of Turkish origin included in our study were mainly second-generation immigrants who had lived in Munich since birth (78.2\%).

Changes in dietary habits might be related to the low prevalence of asthma and atopy in Turkish children living in Germany. Although we do not have any data on the dietary habits of our study population, it seems unlikely that the Turkish children would differ in their dietary intake from Turkish children living in Turkey, unless the dietary habits of Turkish urban and rural populations were different.

None of the other environmental risk factors we assessed, including pets, passive smoking, number of siblings and family history of asthma, sufficiently explained the effect of Turkish origin in our multivariate analyses. Therefore, the presence of a selection bias due to the immigration of more healthy people still seems likely. Gene/environment interactions could provide an alternative explanation for the observed differences in asthma prevalence between Turkish and German children living in Germany. However, our study design was not aimed at answering questions of gene/environment interaction and therefore our data do not provide a means of discussing this issue. We completely agree with the final conclusion drawn by A. Fuat Kalyoncu and Z.T. Selçuk that studying groups of different ethnic origin within a population is a valuable tool for the identification of risk factors for asthma and atopy. Furthermore, studies of gene/environment interactions including minorities are needed in the framework of an international and European cooperation.

\section{Kabesch, E. von Mutius}

Ludwig Maximilian University, Dr von Haunersche Kinderklinik, D-80337 Munich, Germany. Fax: 15206266970.

\section{References}

1. Kabesch M, Schaal W, Nicolai T, von Mutius E. Lower prevalence of asthma and atopy in Turkish children living in Germany. Eur Respir J 1999; 13: 577-582.

2. Grueber C, Plieth A, Taner C, Schmidt D, Sommerfeld C, Wahn U. Less allergic sensitization, wheezing, and itching eczema in Turkish children than in German children raised in Berlin, Germany. J Allergy Clin Immunol 2000; 105: S32.

3. Tuerktas I, Selçuk ZT, Kalyoncu AF. Prevalence of asthma and wheezing in Turkish children. Eur Respir J 1998; 12: 52s.

4. Kalyoncu AF, Selçuk ZT, Karakoca Y, et al. Prevalence of childhood asthma and allergic diseases in Ankara, Turkey. Allergy 1994; 49: 485-488.

5. Kucukoduk S, Aydin M, Cetinkaya F, Dinc H, Gurses N, Saraclar Y. The prevalence of asthma and other allergic diseases in a province of Turkey. Turk J Pediatr 1996; 38: 149-153.

6. Selçuk ZT, Caglar T, Enunlu T, Topal T. The prevalence of allergic diseases in primary school children in Edirne, Turkey. Clin Exp Allergy 1997; 27: 262-269.

7. Ones U, Sapan N, Somer A, et al. Prevalence of childhood asthma in Istambul, Turkey. Allergy 1999; 13: 577-582. 